\title{
Case Report \\ Successful Percutaneous Retrieval of Embolized Septal Occluder Device from Aortic Arch and Placement of a Newer Septal Occluder Device in Combined Procedure
}

\author{
Natraj Katta, Sandeep Gautam, and Richard Webel \\ Division of Cardiovascular Medicine, University of Missouri School of Medicine, Columbia, MO, USA \\ Correspondence should be addressed to Natraj Katta; kattan@health.missouri.edu
}

Received 25 October 2016; Accepted 14 December 2016

Academic Editor: Ramazan Akdemir

Copyright (C) 2016 Natraj Katta et al. This is an open access article distributed under the Creative Commons Attribution License, which permits unrestricted use, distribution, and reproduction in any medium, provided the original work is properly cited.

\begin{abstract}
Embolization of the Amplatzer Septal Occluder (ASO) device (St. Jude Medical, Minnesota) after percutaneous closure of atrial septal defect (ASD) is a rare and potentially catastrophic complication. Percutaneous retrieval of the embolized device is gaining ground as an acceptable method, although these patients are usually subsequently referred for open surgical closure of the ASD. We present a unique case of percutaneous retrieval embolized ASO device and placement of newer larger ASO device in a single procedure.
\end{abstract}

\section{Case Report}

A 75-year-old female patient with history of persistent atrial fibrillation after multiple failed cardioversions and septum secundum type of ASD presented with worsening exertional dyspnea of six-month duration. She was previously intolerant to amiodarone. She underwent elective catheter based atrial fibrillation ablation followed by closure of the ASD during a combined percutaneous procedure. ASD closure was performed using a $16 \mathrm{~mm}$ Amplatzer Septal Occluder (ASO) device after measuring the diameter of the defect at $15.4 \pm 1.0 \mathrm{~mm}$ (Figure 1(a)) with sizing balloon and $15 \mathrm{~mm}$ (Figure 1(b)) with intracardiac echocardiogram (ICE). After the deployment of the device, ICE showed minimal residual shunt flow confirming correct position. The following day, a transthoracic echocardiogram (TTE) revealed severe right to left shunt indicating recurrence of ASD, without visualization of the ASO device. A chest radiograph (Figure 2(a)) showed the embolized ASO device in the aortic arch. Patient had no new symptoms except recurrence of atrial fibrillation requiring cardioversion. Patient was taken to cardiac catheterization laboratory for possible percutaneous retrieval of the embolized ASO device and placement of a newer device. $6 \mathrm{~F} \times 11 \mathrm{~cm}$ sheath was placed in right femoral artery. Aortic arch angiography was performed with a $5 \mathrm{~F} \times 110 \mathrm{~cm}$ pigtail catheter (Figure 2(b)). $6 \mathrm{~F}$ sheath was then exchanged with a $10 \mathrm{~F} \times 80 \mathrm{~cm}$ long cook sheath (Cook Medical Inc. Indiana). Using 6 F 12-20 $\mathrm{mm} \times 120 \mathrm{~cm}$ En-Snare System (Merit Medical Systems, Inc., Utah) through a $6 \mathrm{~F}$ Hockey Stick II guiding catheter (Medtronic Inc., Minnesota), we were able to snare the metallic tip on the right atrial disc of ASO device (Figure 2(c)). Subsequently, entire device was collapsed into the long sheath which was safely removed (Figure 2(d)). Thereafter, a $20 \mathrm{~mm}$ ASO device placed using a 9 F Amplatzer delivery system (St. Jude Medical, Minnesota), after resizing of the defect. This time the sizing balloon yielded diameter of $17.41 \mathrm{~mm}$ (Figure 3(a)) and ICE of $18 \mathrm{~mm}$ (Figure 3(b)). Both ICE and TTE showed properly positioned ASO device with minimal residual shunt. No procedure related complications occurred. Patient was discharged 2 days later.

\section{Discussion}

The incidence of occluder device embolization after ASD closure is $0.55 \%-1.4 \%[1,2]$. Nearly half of the embolized ASO devices tend to lodge in the left atrium and aorta [3]. According to the MAUDE (Manufacturer and User Facility Device Experience) database, only a minority (16.7\%) of embolized devices are retrieved using percutaneous 


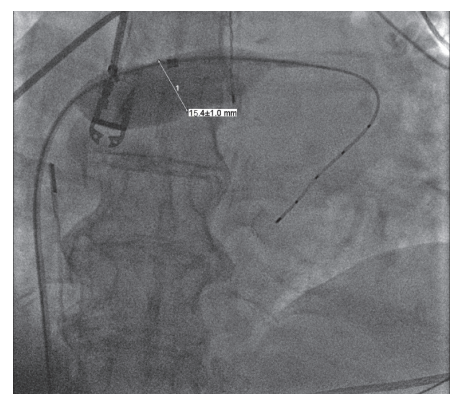

(a)

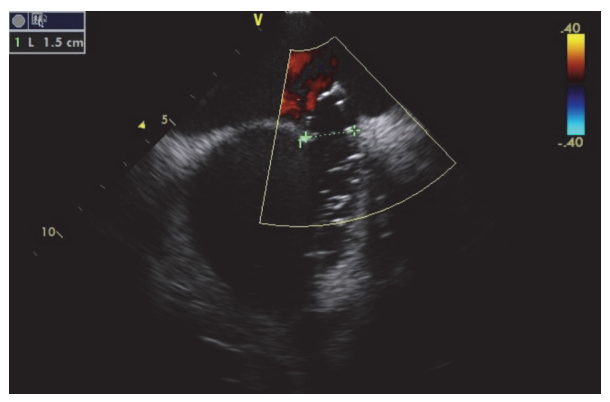

(b)

FIGURE 1: (a) Sizing balloon showing the diameter of the ASD. (b) Intracardiac echocardiogram showing the diameter of the ASD.

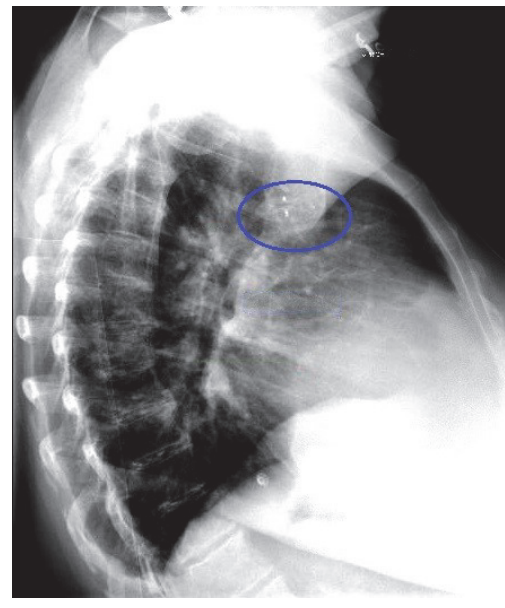

(a)

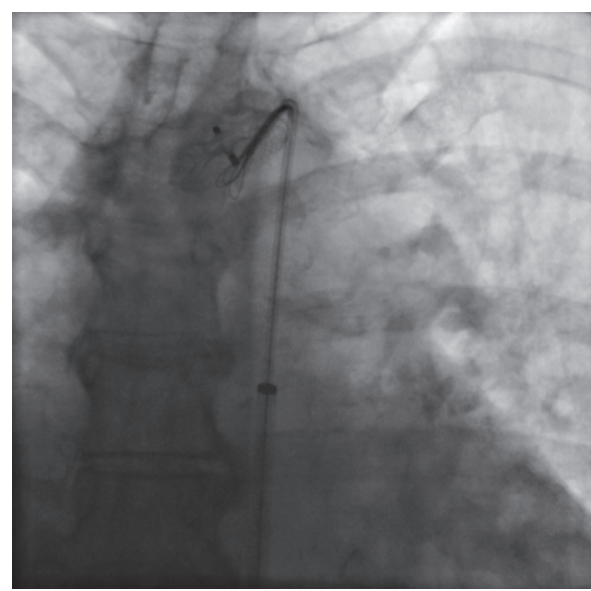

(c)

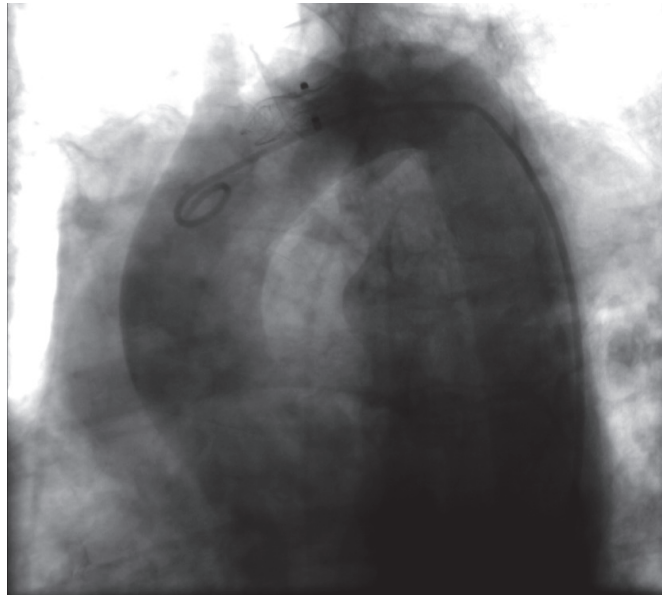

(b)

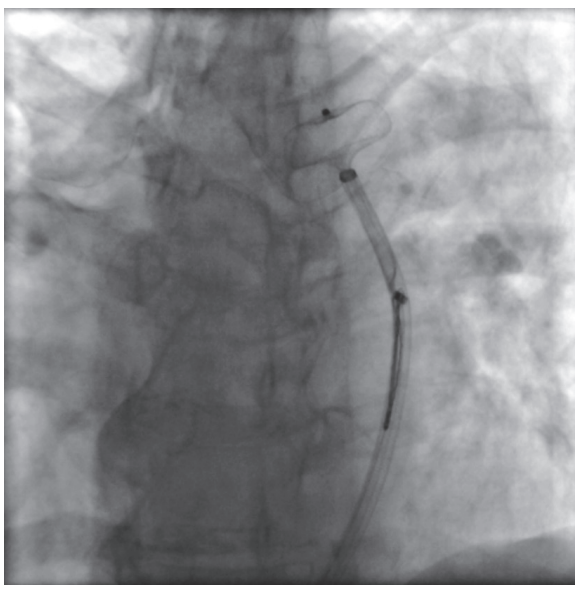

(d)

FIGURE 2: (a) Chest radiograph, lateral view showing the embolized ASO. (b) Aortic arch angiography using angled pigtail catheter. (c) Using En-Snare, capturing of the metallic tip of the right atrial disc of the ASO. (d) Retraction of the entire ASO into the long cook sheath.

approach [2]. Undersized device, floppy or inadequate rim, device malposition, and excessive tension on the delivery cable during the deployment are the possible mechanisms for device embolization [2]. In our case, we believe that undersizing was the possible mechanism, which in turn was probably due to noncircular shape of the defect. In previous case reports, Gooseneck type of snare system was used [46], whereas we are able to retrieve the device using the En-Snare System, showing that there are various options in choosing the retrieval system, although merits of one system over the others are unclear. According to a survey of the ASO company-designated proctors, approximately half of 


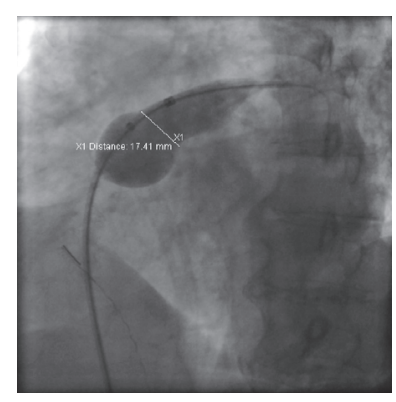

(a)

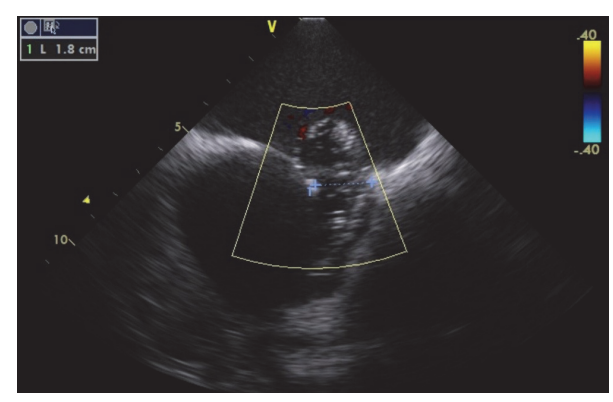

(b)

FIGURE 3: (a) Resizing of the ASD using the sizing balloon. (b) Resizing of the ASD using the intracardiac echocardiogram.

the patients had percutaneous closure of the ASD after the embolized device retrieval, but it is not reported whether they were done as a combined procedure or at a later date [7]. To the best of our knowledge, our case is the first reported case of percutaneous retrieval of embolized device and percutaneous placement of newer device performed as combined procedure. We also performed atrial fibrillation ablation with ASD closure on the same day. As arrhythmia control is difficult to achieve with ASD closure alone in patients with atrial fibrillation and technical challenges associated with transseptal access after device closure, it is considered appropriate to perform atrial fibrillation ablation prior to ASD closure $[8,9]$.

\section{Conclusion}

Percutaneous retrieval of the embolized ASO device is still not widely performed. Also, there is no consensus regarding the appropriate timing of the reclosure of the ASD percutaneously after the retrieval of embolized device. With proper planning, percutaneous retrieval and placement of newer device can be safely performed in single setting. We also believe that, in patients with atrial fibrillation and atrial septal defect, it is reasonable to perform atrial fibrillation ablation prior to ASD closure.

\section{Competing Interests}

The authors declare that there is no conflict of interests regarding the publication of this paper.

\section{References}

[1] M. M. Amanullah, M. T. Siddiqui, M. Z. Khan, and M. A. Atiq, "Surgical rescue of embolized amplatzer devices," Journal of Cardiac Surgery, vol. 26, no. 3, pp. 254-258, 2011.

[2] J. Moore, S. Hegde, H. El-Said et al., "Transcatheter device closure of atrial septal defects: a safety review," JACC: Cardiovascular Interventions, vol. 6, no. 5, pp. 433-442, 2013.

[3] D. J. DiBardino, D. B. McElhinney, A. K. Kaza, and J. E. Mayer Jr., "Analysis of the US Food and Drug Administration Manufacturer and User Facility Device Experience database for adverse events involving Amplatzer septal occluder devices and comparison with the Society of Thoracic Surgery congenital cardiac surgery database," The Journal of Thoracic and Cardiovascular Surgery, vol. 137, no. 6, pp. 1334-1341, 2009.

[4] A. S. Basoor, J. F. Cotant, A. R. Halabi, M. DeGregorio, H. Chughtai, and K. C. Patel, "Minimally invasive retrieval of patent foramen ovale closure device: after device migration to the descending aorta," Texas Heart Institute Journal, vol. 39, no. 4, pp. 582-584, 2012.

[5] J. Y. Cho, K. H. Kim, H. J. Yoon et al., "Percutaneous retrieval of embolized Amplatzer Septal Occluder after treatment of double atrial septal defect: a case report," Journal of Korean Medical Science, vol. 30, no. 9, pp. 1361-1366, 2015.

[6] M. Guimaraes, C. E. Denton, R. Uflacker, C. Schonholz, B. Selby Jr., and C. Hannegan, "Percutaneous retrieval of an Amplatzer septal occluder device that had migrated to the aortic arch," CardioVascular and Interventional Radiology, vol. 35, no. 2, pp. 430-433, 2012.

[7] D. S. Levi and J. W. Moore, "Embolization and retrieval of the Amplatzer septal occluder," Catheterization and Cardiovascular Interventions, vol. 61, no. 4, pp. 543-547, 2004.

[8] F. Berger, M. Vogel, A. Kramer et al., "Incidence of atrial flutter/fibrillation in adults with atrial septal defect before and after surgery," Annals of Thoracic Surgery, vol. 68, no. 1, pp. 7578, 1999.

[9] J.-G. Nie, J.-Z. Dong, M. Salim et al., "Catheter ablation of atrial fibrillation in patients with atrial septal defect: long-term follow-up results," Journal of Interventional Cardiac Electrophysiology, vol. 42, no. 1, pp. 43-49, 2015. 


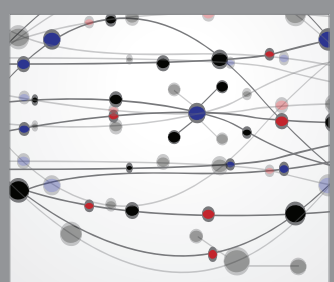

The Scientific World Journal
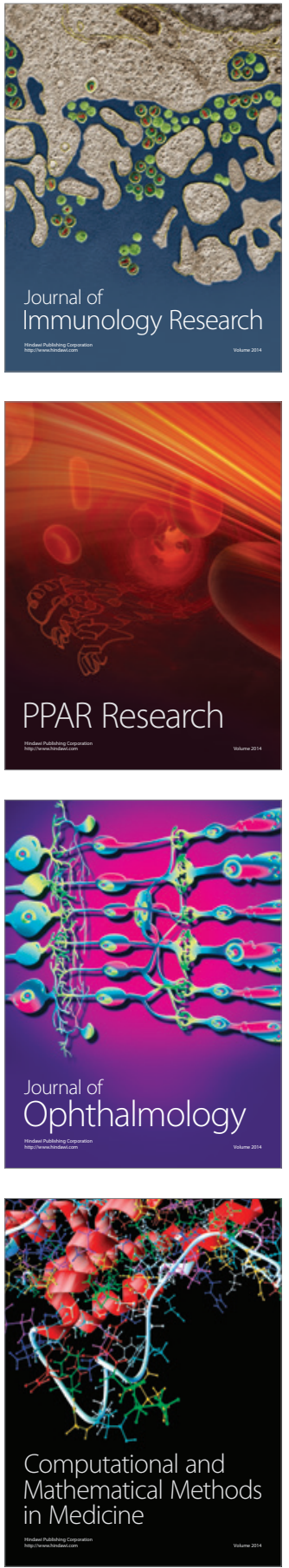

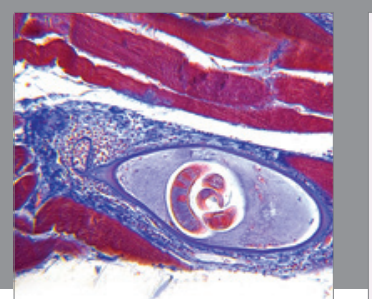

Gastroenterology Research and Practice

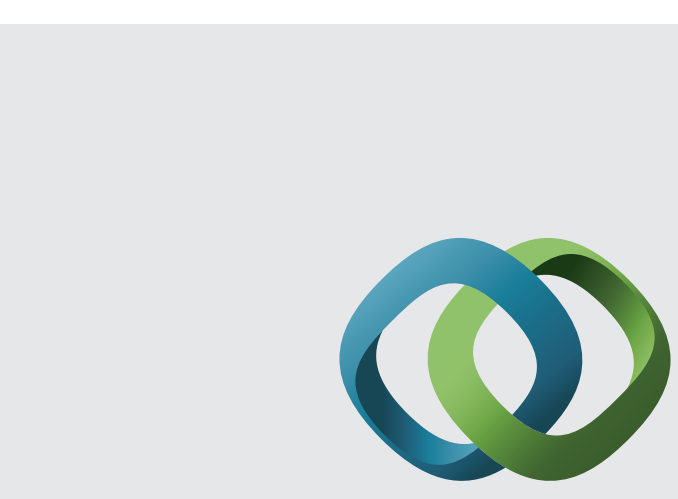

\section{Hindawi}

Submit your manuscripts at

http://www.hindawi.com
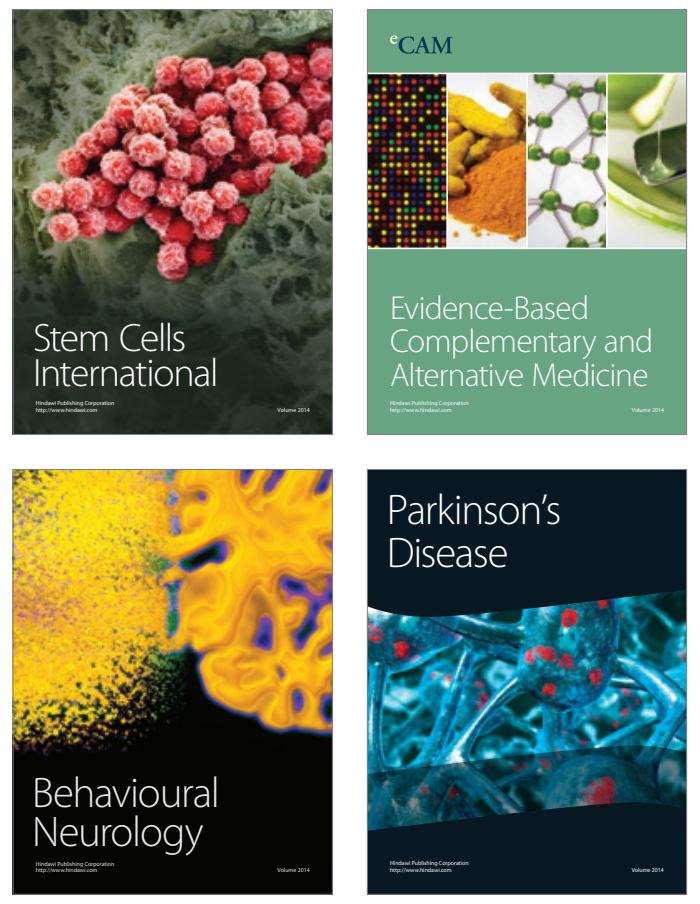
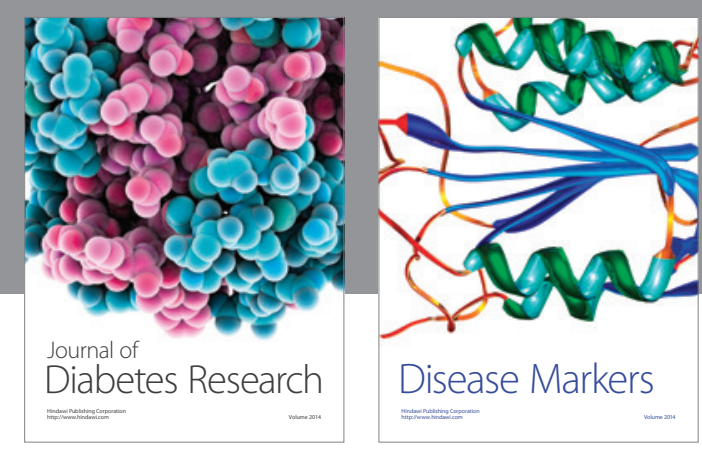

Disease Markers
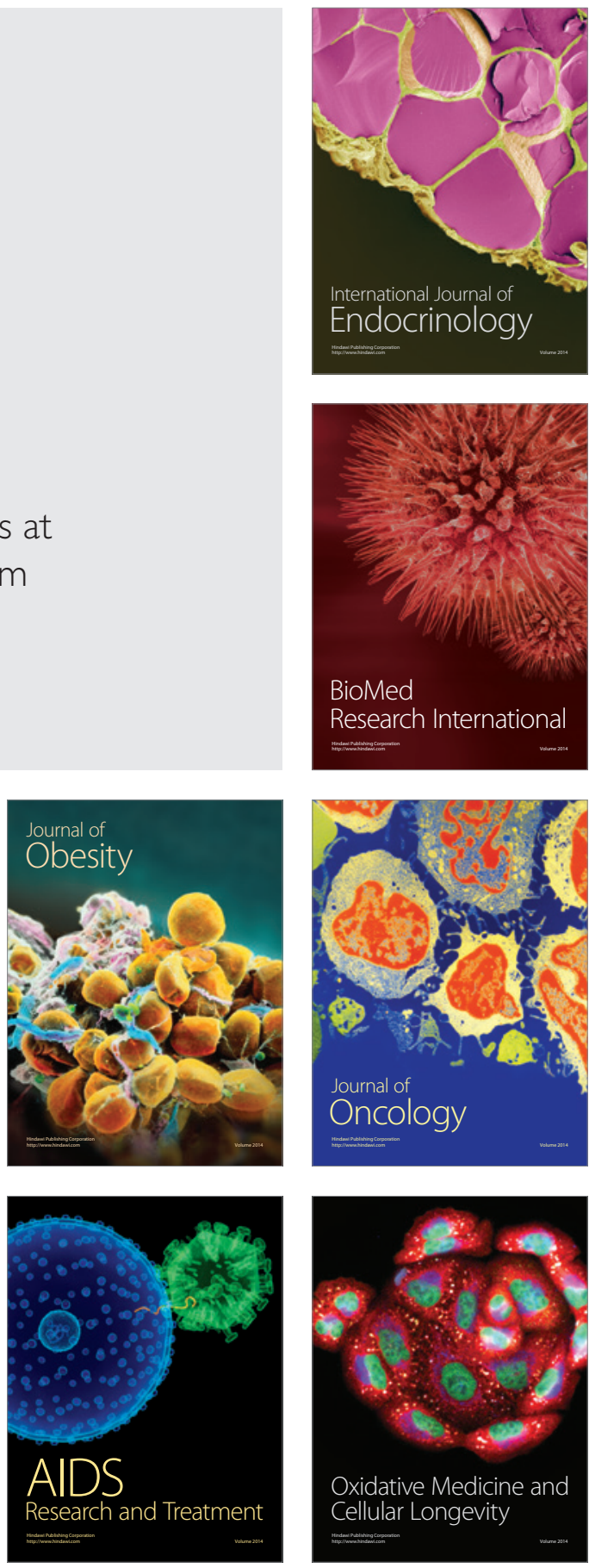